\title{
Bilateral Aberrant C1/2 Intradural Vertebral Arteries: a Rare Cause of Cervical Myelopathy
}

\begin{tabular}{|r|l|}
\hline Journal: & ANZ Journal of Surgery \\
\hline Manuscript ID: & ANS-2014-00571.R1 \\
\hline Danuscript Type: & Images for Surgeons \\
\hline Complete List of Authors: & $\begin{array}{l}\text { Tsang, Anderson; The University of Hong Kong, Surgery } \\
\text { Tsang, Frederick; Queen Mary Hospital, Neurosurgery } \\
\text { Lui, Wai Man; Queen Mary Hospital, Neurosurgery }\end{array}$ \\
\hline General Key Words: & Neurosurgery \\
\hline Specialty Key Words: & Cervical myelopathy, Vertebral artery \\
\hline
\end{tabular}

\section{SCHOLARONE ${ }^{\text {m }}$ \\ Manuscripts}




\title{
Bilateral Aberrant C1/2 Intradural Vertebral Arteries: a Rare Cause of Cervical Myelopathy
}

\author{
Authors: \\ Anderson Chun On Tsang, ${ }^{1,2}$ MBBS, Frederick Chun Pong Tsang, ${ }^{2}$ MBBS FCSHK, \\ Wai Man Lui, ${ }^{2}$ MBBS, FCSHK \\ Affiliations: \\ ${ }^{1}$ Department of Surgery, Li Ka Shing Faculty of Medicine, The University of Hong \\ Kong, Hong Kong; \\ ${ }^{2}$ Department of Neurosurgery, Queen Mary Hospital, Hong Kong
}

Corresponding author:

Dr Anderson C.O. Tsang, Division of Neurosurgery, Department of Surgery, Li Ka

Shing Faculty of Medicine, The University of Hong Kong, Queen Mary Hospital, 102

Pokfulam Road, Hong Kong. Tel: (852) 22553368; Fax: (852) 28184350; Email:

acotsang@hku.hk.

\section{Running Title:}

Cervical myelopathy due to compression of aberrant vertebral arteries 
The corresponding author is not a recipient of a research scholarship.

The content of this paper is never published or presented in any medical conference.

3 figures are included in this paper.

Word count: 732 (Text)

16

17

18

19

20

21

22

23

24

25

26

27

28

29

30

31

32

33

34

35

36

37

38

39

40

41

42

43

44

45

46

47

48

49

50

51

52

53

54

55

56

57

58

59

60 
A 65-year-old lady presented with progressive cervical myelopathic symptoms

for 4 years. She complained of bilateral upper limbs numbness and weakness initially, associated with clumsiness of fine hand movements. The motor power of both upper limbs gradually deteriorated to grade 4 out of 5 . Her symptoms then progressed to the lower limbs with stiff and clumsy gait in recent two months. There was no sphincter disturbance or neck pain. Physical examination revealed bilateral brisk tendon reflexes, positive Hoffman's sign and finger escape on both hands, confirming the clinical diagnosis of cervical myelopathy.

MRI of the cervical spine showed prominent vessel loops compressing the cervical cord bilaterally at the cranio-cervical junction. (Fig. 1) The bony alignment was normal and there were no significant degenerative changes or other cord-compressing lesions. CT-angiogram of the head and neck region confirmed the culprit vessels were the co-dominant vertebral arteries (VA) with an aberrant course. Normally, both VA exit the foramen transversarium of $\mathrm{C} 1$, then curve medially along the superior aspect of the posterior arch of $\mathrm{C} 1$, before entering the posterior ligaments and the dura at the foramen magnum to continue the intracranial course. In our patient, both vertebral arteries pierced the dura between the axis and the atlas, after exiting the foramen transversarium of $\mathrm{C} 2$ without going through the $\mathrm{C} 1$ foramen transversarium. 
This gave rise to an aberrant intraspinal intradural course from the level of the atlas, causing compressive cervical myelopathy. (Fig. 2)

\author{
Limited suboccipital craniectomy with $\mathrm{C} 1$ laminectomy was performed for \\ decompression. The spinal cord showed indentations by both VA, (Fig. 3) which were \\ mobilized free from the cord and anchored. The thecal sac was enlarged for better \\ decompression. The somatosensory evoked potential of all four limbs improved \\ intra-operatively.
}

Patient's symptoms improved spontaneously after the operation. Post-operative MRI showed partial re-expansion of the previously compressed $\mathrm{C} 1$ cord, with both VAs now displaced laterally and not in contact with the cord. At 6 months after decompression, she can walk independently, with full motor power in all four limbs. The numbness and tightness of the extremities also resolved except over the left arm, where the symptoms first appeared. She was able to return to work without limitations Anatomical variations of the distal VAs are well documented but rarely symptomatic. Only four symptomatic cases of VA entering dura between C1/2 levels had been reported in the literature. ${ }^{1-4}$ This variation is due to persistence of the spinal branch of 
the embryological Type 2 Proatlantal artery, which normally regresses during VA development. Such variation could result in duplication or aberrant course of distal VA, and is first recognized by Lasjaunias et al. ${ }^{5}$ In case of duplication, the aberrant C1/2 entrance of VA may co-exist with a normal foramen of magnum entering branch.

In our patient, the $\mathrm{C} 1 / 2$ branch was dominant while the typical course of VA was absent, resulting in an aberrant course of distal VA. Other anatomical variations that can occur in the distal VA include $\mathrm{C} 1$ or $\mathrm{C} 2$ origin of the Posterior inferior cerebellar artery. $^{6}$

Our patient became symptomatic at 60 years of age, similar to previous reported cases when symptom onset was from 50 to 70 years old. ${ }^{1-4}$ It is unclear why such congenital anatomical variation should become symptomatic only in the late adulthood. We surmise it may be due to chronic pulsatile stimulation of the spinal cord by the VAs, coupled with a progressive narrowing of spinal canal secondary to degeneration, leading to myelopathy eventually.

Microsurgical release of the compressing VA together with decompressive laminectomy is an effective treatment. We used autologous fascia graft harvested from the cervical muscles as a sling to secure both VAs away from the cord surface. 
Synthetic materials such as Teflon sponge has also been used to separate the VA from the cord. ${ }^{2,3}$ Although that served to buffer the pulsatile stimulation from the vessel, the cord was still physically in contact and compressed by the VA and sponge. We believed anchoring the VA and releasing it from contact of the cord would provide more lasting symptomatic relief. Improvements in the intraoperative somato-sensory evoked potential monitoring and expansion of the previously compressed cord in the post-operative MRI confirmed satisfactory decompression.

In conclusion, we presented a rare case of cervical myelopathy due to bilateral vertebral arteries compression at $\mathrm{C} 1$ level, secondary to the persistence of intradural Type 2 proatlantal artery. Laminectomy and microvascular decompression with autologous fascia graft resulted in resolution of symptoms.

\section{References:}

1. Ball BG, Krueger BR, Piepgras DG. Anomalous vertebral artery compression of the spinal cord at the cervicomedullary junction. Surgical neurology international 2011;2:103.

2. Ha EJ, Lee SE, Jahng TA, Kim HJ. Cervical Compressive Myelopathy due to Anomalous Bilateral Vertebral Artery. Journal of Korean Neurosurgical Society 2013;54:347-9.

3. Shah A, Mahore A, Goel A. Bilateral vasculopexy of anomalous vertebral arteries causing cervicomedullary compression: case report and technical note. European 
spine journal : official publication of the European Spine Society, the European Spinal Deformity Society, and the European Section of the Cervical Spine Research Society 2012;21 Suppl 4:S505-8.

4. Takei H, Sagae M, Chiba K, Ogino T. The long-term follow-up of surgical treatment for cervical myelopathy with severe nape and upper arm pain caused by the anomalous vertebral artery: case report. Spine 2008;33:E611-3.

5. Lasjaunias P, Vallee B, Person H, Ter Brugge K, Chiu M. The lateral spinal artery of the upper cervical spinal cord. Anatomy, normal variations, and angiographic aspects. J Neurosurg 1985;63:235-41.

6. Siclari F, Burger IM, Fasel JH, Gailloud P. Developmental anatomy of the distal vertebral artery in relationship to variants of the posterior and lateral spinal arterial systems. AJNR Am J Neuroradiol 2007;28:1185-90.

\section{Figure Legends}

Fig. 1: Sagittal T2 MRI of the cervical spine, showing aberrant vessel loop compressing spinal cord at C1 level.

Fig. 2: Coronal reconstruction of CT angiogram of the neck, showing bilateral aberrant vertebral arteries entering the spinal canal between $\mathrm{C} 1$ and $\mathrm{C} 2$, with compression of the cord.

Fig. 3: Intraoperative view under operating microscope showing bilateral aberrant vertebral arteries compressing the cord. 


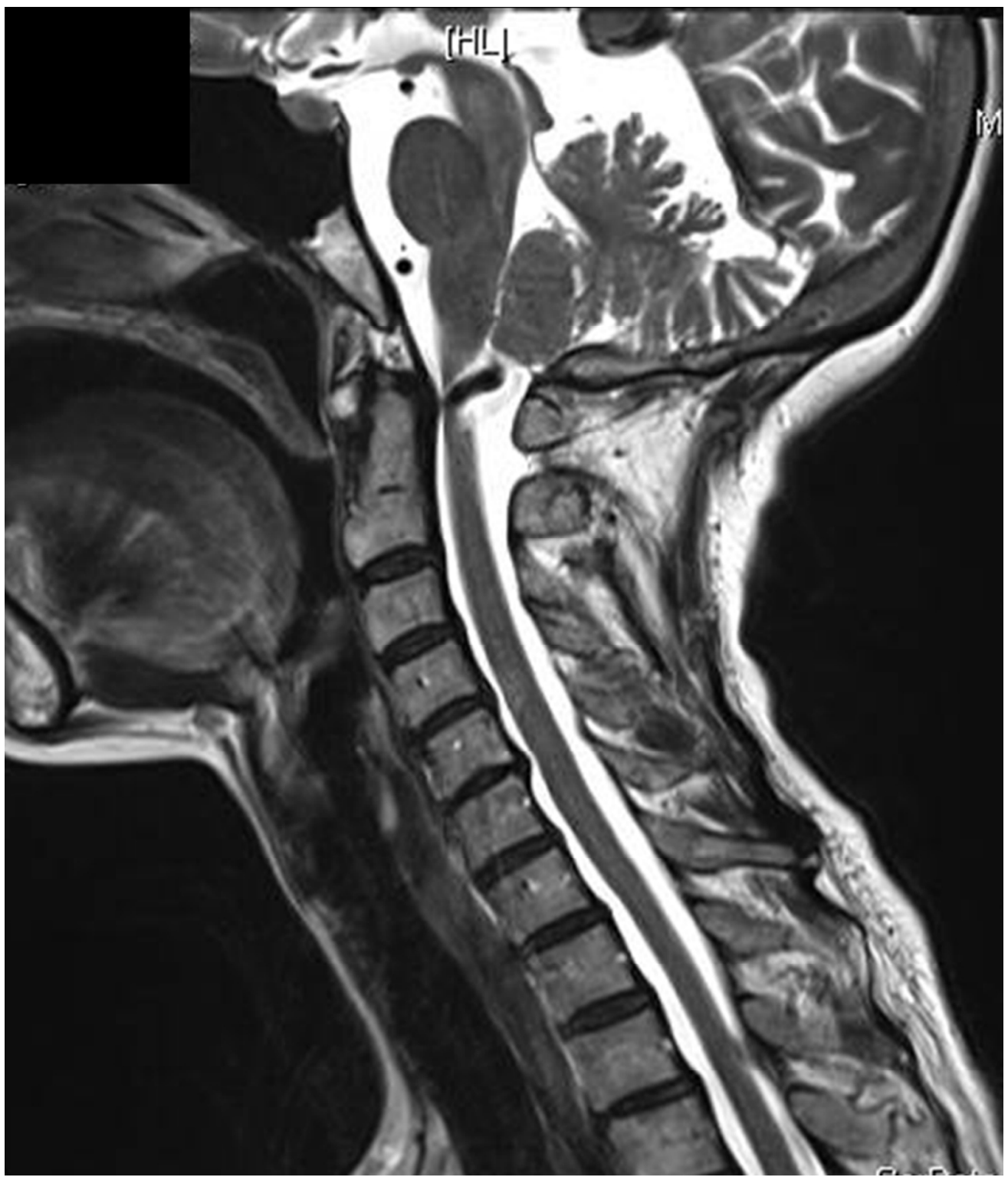

Sagittal T2 MRI of the cervical spine, showing aberrant vessel loop compressing spinal cord at C1 level. $101 \times 119 \mathrm{~mm}(300 \times 300 \mathrm{DPI})$

50

51

52

53

54

55

56 


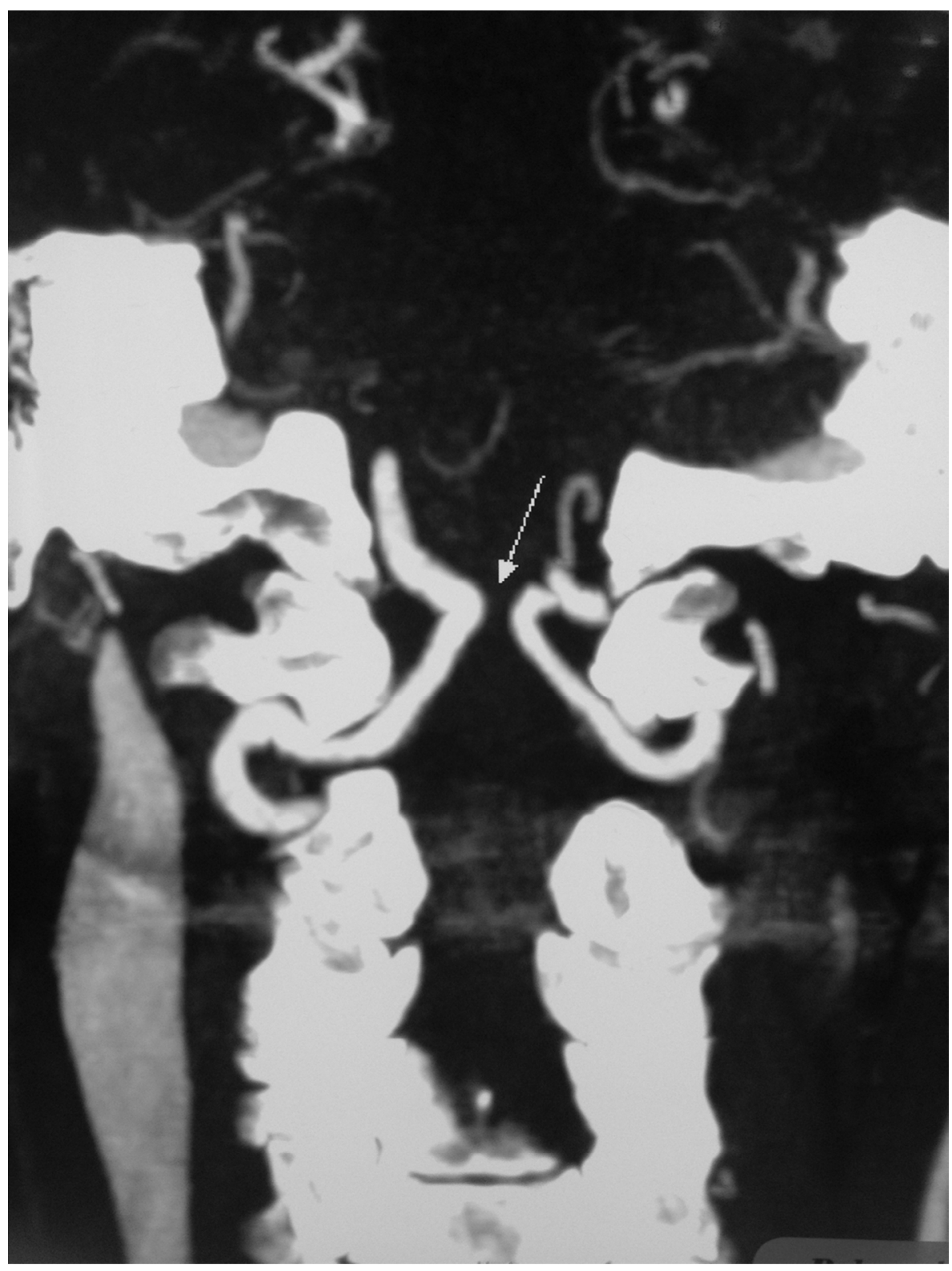

Coronal reconstruction of $\mathrm{CT}$ angiogram of the neck, showing bilateral aberrant vertebral arteries entering the spinal canal between $\mathrm{C} 1$ and $\mathrm{C} 2$, with compression of the cord. $101 \times 135 \mathrm{~mm}(300 \times 300 \mathrm{DPI})$ 


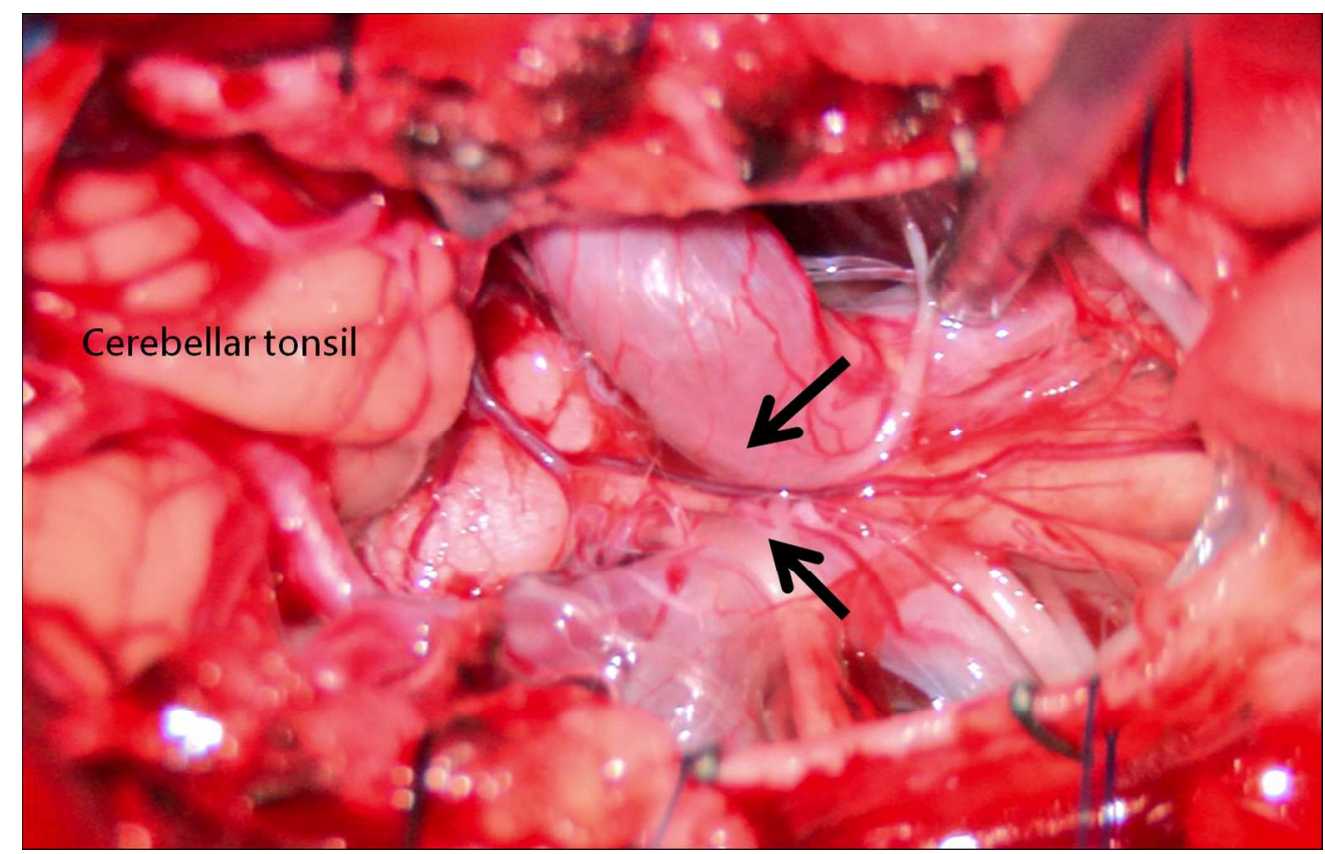

Intraoperative view under operating microscope showing bilateral aberrant vertebral arteries (arrow) compressing the cord. $177 \times 114 \mathrm{~mm}(300 \times 300$ DPI $)$ 